\title{
I ntegrating the scholarship of practice into the nurse academician portfolio
}

\author{
Kathleen Peterson, J oanne Stevens \\ The College at Brockport, The State University of New York, NY, USA. \\ Correspondence: Kathleen Peterson. Address: The College at Brockport, The State University of New York, 350 New \\ Campus Drive, Brockport, NY 14420, USA. Email: kpeterso@brockport.edu. \\ Received: July 23, 2012 \\ DOI : 10.5430/jnep.v3n11p84
}

\section{Abstract}

Many nurse academicians are also advanced practice nurses (APNs) in the United States (U.S.). Such faculty are often involved in clinical practice activities which require specific competencies for meeting legal responsibilities and standards for safety. Maintaining practice expectations often takes away the time necessary to address traditional scholarship expected by U.S. institutions for advancement and promotion, and securing tenured academic positions. Scholarship activities for APNs should encompass broad and essential criteria during review and promotional processes; especially important is documentation for the scholarship of application as it applies to APN clinical practice. Nursing faculty who practice as APNs should become adept at documenting scholarship of practice. Appropriate recognition for valid non-traditional types of scholarship activities is essential.

According to the Position Statement of the American Association of the Colleges of Nursing (AACN) on Defining Scholarship for the Discipline of Nursing, there are four different dimensions of scholarship. These expand upon the seminal work of Boyer (1990) and consist of: (a) the Scholarship of Discovery, (b) the Scholarship of Teaching, (c) the Scholarship of Application, and (d) the Scholarship of Integration. The purpose of this article is to describe each of the four types of scholarship and demonstrate how the APN/ nurse academician's clinical practice is an application of scholarship. APN practice is multidimensional and an important basis for review and promotion in academic and/or health care settings.

\section{Key words}

Scholarship, Practice, Academe, Portfolio

\section{Introduction}

Academia is becoming very competitive and challenging, particularly when considering the detailed processes involved in review for promotion in rank and securing tenured, permanent positions. To obtain tenure a faculty member completes a rigorous body of scholarly products and professional reviews (e.g. tenure portfolio) over the course of seven years, usually while working at an Assistant Professor. Once tenure is approved faculty are promoted to the rank of Associate Professor. In our institution, after holding the rank of Associate Professor for five years, and continuing to produce additional scholarship while being an expert teacher and providing service to the college, community and profession of nursing, a 
faculty member may apply for promotion to Professor. Nursing faculty is held to the same scholarship standards as other departments within our college or university system in terms of the amount of scholarship that is produced. Unlike other professors within a college or university setting, nursing academicians have substantial additional responsibilities and professional standards associated with clinical practice that are required and essential to the profession. The research model embedded in traditional universities often focuses on discipline specific research construed within the basic or natural sciences, which may devalue those academic disciplines that fulfill professional mandates such as nursing ${ }^{[1]}$.

Many nurse academicians are also advanced practice nurses (APN/nurse academician) who are involved in clinical practice activities. They are required to maintain competencies and certification as well as legal responsibilities for safe practice. APNs, as faculty also serve as role models for students in the clinical setting. Practicing as a nurse in a health care setting assists nursing faculty to remain current and knowledgeable of changing health care management and integrative systems. Practice in turn impacts patients' wellness indicators and positively affects teaching and learning for nursing students. The downside of spending time in practice is that it competes with the time needed to produce "traditional" scholarship, primarily research and publication. Administration and faculty in other disciplines in the academic setting are often oblivious to the importance of maintaining an active clinical practice for nursing faculty. It is our experience that college administration, as well as colleagues on campus, often do not understand the time, effort, and importance that APN/nurse academicians place on clinical practice, or the scholarship that comes out of such practice. Thus the nursing faculty at our college has adapted our personnel document that guides tenure and promotion policies. Central in this document is Boyer's (1990) seminal work describing the four dimensions of scholarship. We have successfully promoted the college administration's understanding of the importance of clinical practice as it applies to the Scholarship of Application with this revised document. For example APN certification in a specialty is now recognized as a primary (or major) scholarly product with multi-year reviews (e.g. three to five year review periods). This was a major accomplishment given the time and expertise required to obtain and maintain a specialty practice certification.

Practice provides many opportunities for scholarship; these must be fostered, developed, and shared among nurse academicians. Practice and service are vital to the role of the nursing faculty member, and scholarship produced as a result of these must be acknowledged by the leadership administration of our institutions.

This article describes how our faculty interpret and define the Position Statement on Defining Scholarship for the Discipline of Nursing from statements provided by the AACN ${ }^{[2]}$. We recognize the need to expand and redefine the scholarship of application as it applies to clinical practice and have emphasized "practice" in our Appointment Promotion and Tenure (APT) document. This was completed not only for appropriate recognition for nursing faculty, but as an educational document for peers and colleagues in other disciplines and for college administration and leadership. Simply put, there needs to be a better understanding of our practice as it relates to scholarship activities.

Our college is limited in ability to support major grant awards (such as those provided by the National Institutes of Health) in conducting large research projects that medical and research institutions initiate. Rather our college is primarily vested in educating and preparing students at bachelors and masters' levels. Our institution's mission is excellence in teaching. Fifty percent of our emphasis as full time tenure track faculty is to be in teaching, with 25 percent based in service and 25 percent based in scholarship. Regardless of limited monies to support scholarly activities our faculty is very productive in developing such products.

The primary aim for this article is to describe each of the four types of scholarship germane to the APN/nurse academician role, with a primarily focus on the scholarship of practice. Clinical practice is a common and valued component within academic roles but has little supportive nursing literature as to how it validates nursing scholarship. Our purpose is to demonstrate how the APN/ nurse academician's clinical practice is an application of scholarship that is multidimensional and a basis for review and promotion in academic and/or health care settings. Scholarship in nursing goes beyond traditional publications and presentations and needs to reflect contemporary practice. Nursing faculty are often very 
service oriented, with many maintaining active certification as advanced practice nurses. Though this article speaks to all four aspects of scholarship, the main focus is to provide examples that we have used to expand upon and support the importance of the Scholarship of Nursing Application as it applies to nursing practice.

\section{Defining scholarship for the discipline of nursing}

The general faculty at our college adopted Boyer's (1990) seminal work as the framework for guiding all faculty scholarship in 1998. The nursing faculty also uses the most current position statement that has been adopted by the American Association of Colleges of Nursing (AACN) that also incorporates Boyer's framework for understanding scholarship from various dimensions. According to the Position Statement on Defining Scholarship for the Discipline of Nursing there are four different dimensions of scholarship ${ }^{[2]}$. These expand upon the work of Boyer and are (a) the Scholarship of Discovery, (b) the Scholarship of Teaching, (c) the Scholarship of Application, and (d) the Scholarship of Integration ${ }^{[3]}$. All four types of scholarship are essential to nursing and its professional growth especially for critically thinking and problem solving health care issues in today’s challenging economic climate.

It is important to note that there has been discussion among nursing scholars as to what the best framework is to identify and describe nursing scholarship ${ }^{[1,3-6]}$. Our nursing faculty supports the work of Boyer, not only because his work is imbedded in the AACN position statement, but also because our college's framework for appointment and tenure is modeled after Boyer's work on scholarship.

The following sections provide descriptions of these four interfacing dimensions of scholarship with a targeted explanation of how practice is a common component in each dimension. We have adapted these descriptions into our document that guides renewal, tenure, and promotion.

\subsection{Scholarship of discovery}

Over the past few decades nurses have established the National Institute of Nursing Research with a national nursing agenda. The majority of nurses are knowledgeable on the importance of research based practice ${ }^{[6]}$. According to the AACN position statement, "the scholarship of discovery is the inquiry that produces the disciplinary and professional knowledge that is at the very heart of academic pursuits" ${ }^{22}$. It entails how the practitioner uses the client and family in exploring clinical questions. The scholarship of discovery is diverse and includes: primary empirical research, methodological studies, historical research, theory development and testing, and philosophical inquiry and analysis ${ }^{[2]}$. Nurses demonstrate scholarly discovery in their practice when they question products or methods used or when they evaluate products for patient care ${ }^{[7]}$. Table 1 provides examples of the different venues and products that our faculty have incorporated into promotion packages under the Scholarship of Discovery.

Table 1. Examples of scholarship of discovery

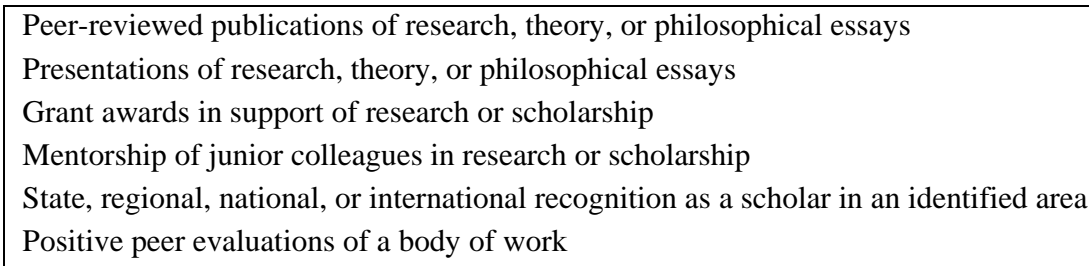

Adapted from AACN Position Statement on Defining Scholarship for the Discipline of Nursing, 1999

\subsection{Scholarship of teaching}

The scholarship of teaching "produces knowledge to support the transfer of the science and art of nursing from the expert to the novice, building bridges between the teacher's understanding and the student's learning” "2]. The AACN position statement clearly outlines and describes ways in which the scholarship of teaching can be conducted by focusing on the 
teaching-learning process, the development of innovative teaching and evaluation methods, program development, learning outcome evaluation, and professional role modeling ${ }^{[2]}$.

Nursing faculty are challenged to continue to offer quality education with the increasing student numbers in the classroom, nursing labs and hospital sites. At the same time faculty are experiencing dwindling faculty lines, limited clinical sites, and less than adequate educational resources. Many nursing faculty have developed innovative ways of continuing excellent instruction given current resources. Successful teaching strategies need to be shared with college and university faculty at large, through publication, podium, and poster presentations. The AACN position statement provides examples of the documentation of the scholarship of teaching and can be viewed in Table 2. Documentation of these activities has assisted our faculty in building a strong portfolio for promotion and tenure. An example is that a faculty member has developed pedagogy of the promotion of critical thinking in post clinical conferences that has been adapted by other faculty members, and has been shared by publication ${ }^{[8]}$.

Table 2. Examples of the scholarship of teaching

Peer-reviewed publications of research related to teaching methodology or learning outcomes, case studies related to teaching-
learning, learning theory development, and development or testing of educational models or theories
Accreditation or other comprehensive program reports
Successful applications of technology to teaching and learning
Positive peer assessments of innovations in teaching
State, regional, national, or international recognition as a master teacher
Published textbooks or other learning aids
Grant awards in support of teaching and learning
Design of outcome studies or evaluation/assessment programs
Presentations related to teaching and learning

Adapted from AACN Position Statement on Defining Scholarship for the Discipline of Nursing, 1999

\subsection{Scholarship of integration}

Nursing is well known for its holistic and multidisciplinary approaches ${ }^{[4,6]}$. Nursing faculty are challenged to foster scholarship of discovery and integration particularly in new generations of nurses ${ }^{[4]}$. According to the AACN Position Statement on Defining Scholarship for the Discipline of Nursing, the Scholarship of Integration consists of "writings and other products that use concepts and original works from nursing and other disciplines in creating new patterns, placing knowledge in a larger context, or illuminating the data in a more meaningful way" ${ }^{[2]}$. The scholarship of integration emphasizes the interconnection of ideas, and brings new insight to bear on original concepts and research. This type of scholarship associates research with reality and clarifies the meaning of results ${ }^{[7]}$.

Table 3. Examples of the scholarship of integration

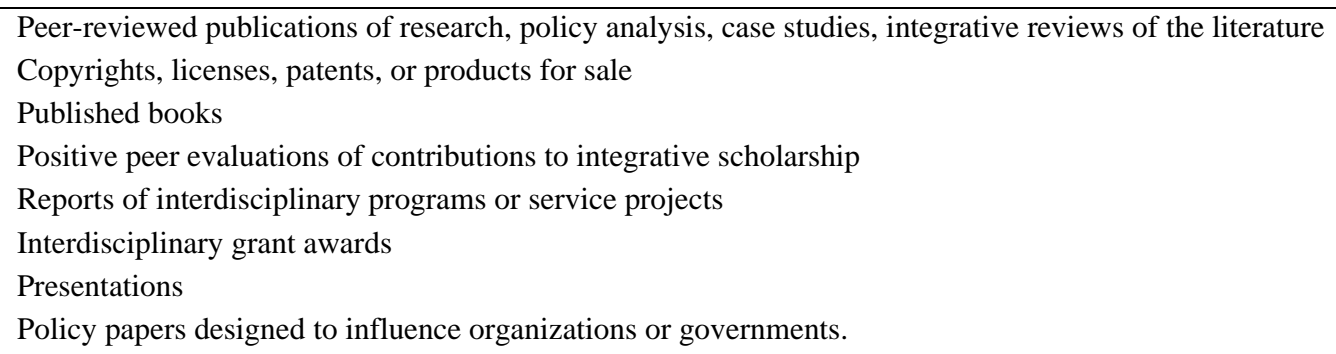

Adapted from AACN Position Statement on Defining Scholarship for the Discipline of Nursing, 1999

The Scholarship of Integration occurs when nursing interacts with other disciplines to complete analysis of health policy, development of interdisciplinary educational programs and service projects, integrative reviews of the literature, and integrative models or paradigms across disciplines ${ }^{[2]}$. Scholarship in this context would engage academic and civic 
cultures to creatively collaborate for the benefit of both university and community ${ }^{[9,10]}$. Table 3 lists examples of how the Scholarship of Integration may be included in a promotion and tenure package, many of which our faculty have completed. One example by a faculty member is an integrative oral health screening and referral program that is now considered an evidence based model program for prenatal health ${ }^{[11]}$. This program integrates dentistry, social work, nursing education and midwifery and is a venue for nursing student research projects.

\subsection{Scholarship of application}

Application is clearly germane to practice. Nursing faculty engage in the scholarship of application in a variety of ways including advanced clinical practice, staff development, clinical problem solving, and consultation work. The scholarship of application is discipline specific and may not result in a product in the traditional sense of the word, but may result in products that allow for practice application such as policy development, practice protocols, care pathways or manuals. For the purposes of appointment to a particular academic level of teaching, promotion and tenure in securing an academic position, this type of scholarship is best supported by letters of support from those who have benefited from such products. An example is an interactive educational design for junior nursing student's hospital experiences that not only enhances critical thinking but also interactive learning ${ }^{[8]}$ and has been adopted by other clinical faculty. The scholarship of application allows advanced practice nurses to reflect about clinical practice, think collectively and strategically about advances for best practice, and put processes into place to promote systemic and optimal change across the care continuum $^{[12]}$.This type of scholarship also stimulates research questions specific to populations being served ${ }^{[13]}$. Additionally Starch describes a paradigm shift currently underway that "will fundamentally change the value of practice: the need for universities... to meet the needs of their community" ${ }^{[6]}$. Thus partnering of university to community can provide relevant service with quality outcomes.

Table 4. Examples of multidimensional scholarly practice and application

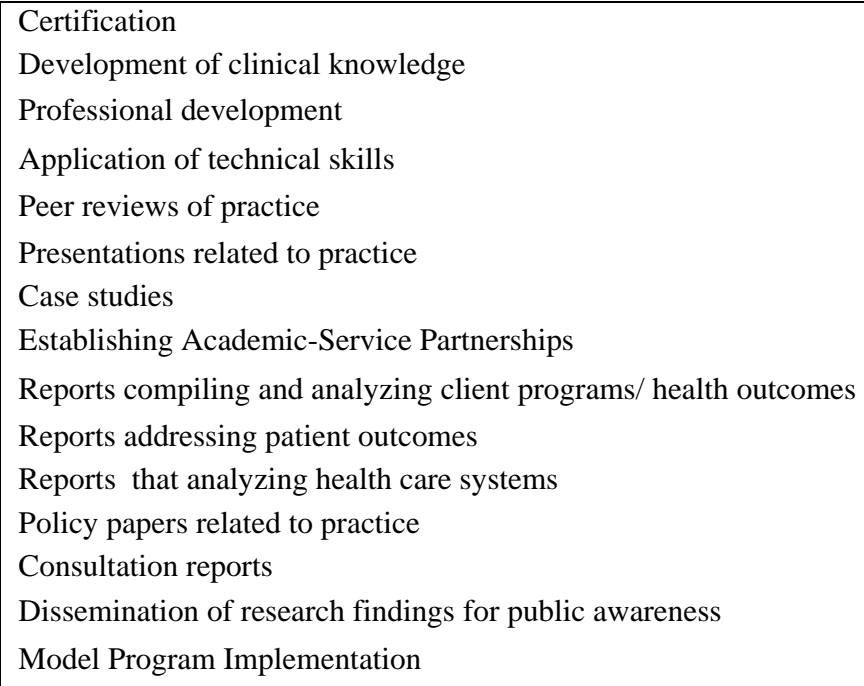

Adapted from AACN Position Statement on Defining Scholarship for the Discipline of Nursing, 1999

According to the AACN Position Statement on Defining Scholarship for the Discipline of Nursing:

Practice is conducted through the application of nursing and related knowledge to the assessment and validation of patient care outcomes, the measurement of quality of life indicators, the development and refinement of practice protocols/ strategies, the evaluation of systems of care, and the analysis of innovative health care delivery models ${ }^{[2]}$.

It is essential for APNs who are academicians to identify problem-focused and knowledge-focused triggers for practice improvements and to promote good care ${ }^{[14]}$. Practicing nurse academicians are crucial to assist in identifying triggers and solving health care problems to improve the quality of health care delivered. 
Remaining active in nursing practice is also an essential part of nursing education by bringing a great wealth of information to the classroom and the nursing lab. As a practice profession, scholarly work and outcomes have a broader definition than in professions which are not practice oriented. The nursing profession clearly engages in the scholarship of empirical research and publication, but there is a fundamental need for defining clinical practice with resultant applications and outcomes as nursing scholarship.

The scholarship of nursing practice links discovery with nursing practice, which is an essential underpinning for practice disciplines such as nursing ${ }^{[5]}$. The scholarship of nursing practice may be the most under-documented of all the types of nursing scholarship, and we have found is the most misunderstood by college and university administration that examine and evaluate promotion and tenure materials. Table 4 lists examples of specific functions and roles associated with scholarly practice and application. The following includes more specific examples of the scholarship of application as it applies to clinical practice.

\section{Certification}

Certification is a significant component within advanced practice nursing as it attests to the knowledge of established standards of practice. Certification allows nurses to ensure that their practice is consistent with established standards of excellence in caring for clients and their families. Obtaining and maintaining certification assures growth in the knowledge and skills of nurses, as well as ensuring that emerging knowledge is obtained. The presence of certification is recognized by accreditation bodies, state education departments and employers as a sign of excellence within the profession. Through certification, nursing faculty promote excellence in practice and teaching. Proof of maintaining certification is in itself a product of scholarship. All of nursing faculty who maintain an active patient practice maintain national certification. The administration of our college now recognizes that attaining initial certification or recertification is equal to a product of scholarship.

\section{Development of clinical knowledge}

Many nursing academicians are immersed in evidence based and expert consensus driven primary and specialty clinical practice arenas to meet the health care needs of individuals, families, communities and populations. Nurse scholars who are involved in practice contribute in a meaningful way to clinical knowledge, and should be acknowledged in the scholarship of application. Nurses who question why certain methods are used and look for improvements in practice are engaging in the development of clinical knowledge and the scholarship of application ${ }^{[7]}$. The development of clinical knowledge may be evidenced by peer review, agency evaluation and maintained through clinical competence.

\section{Professional development}

Advanced practice nurse academicians are required to stay current in best evidence and expert based consensus guidelines. A mandated and essential component for quality clinical practice is earning continuing education units. Evidence of continued study through continuing education units or contact hours (e.g. through conferences, workshops, and reputable on-line resources) represents the scholarship of continuing education within practice. Our faculty who are nationally certified need to maintain an average of 25 to 50 continuing education credits a year (depending on clinical specialty), which provides essential continuing education.

\section{Application of technical skills}

Acquiring new clinical skills by the nurse academician promotes comprehensive health care, but also supports teaching and learning. Learning new skills will add to the care of the clients served and assist student learning. Learning new skills such as colposcopy, incision and drainage, and ultrasound, require ongoing practice and evaluation to maintain competency. Acquisition of technical skills may be evidenced by documentation such as Delineation of Privileges (DOPS) on hospital and ambulatory annual evaluation. Skill acquisition can also be demonstrated by certificates attesting to the completion of such courses of skill and study. 


\section{Peer reviews of practice}

Peer reviews of practicing nurses support responsibility and commitment to scholarship. Peer reviews may attest to the use of evidence-based care and professionalism that is being applied to patient populations. Therefore peer reviews from respectable colleagues within the nurse academician's practice, additionally attest to the scholarship of practice, and may be incorporated into promotion and tenure material.

\section{Presentations related to practice}

As practicing nurse academicians, we are expected to have expertise in our practice area and are asked to present findings related to practice. This is demonstrated in such ways as poster and podium presentations, as well as hospital staff development workshops. Sharing information with colleagues is an accountable component of nurses' roles and is an important dimension of the scholarship of practice ${ }^{[15]}$. Written invitations, recognition letters, certificates, conference materials, and participant evaluations may be included in promotion packages addressing scholarship as a result of presentations.

\section{Case studies}

The beauty of practice for nurse academicians is a constant flow of case studies from practice to use in enhancing the classroom experience. Case studies augment teaching, providing real life situations from which the students learn. Case studies can provide a basis for interactive course work and for promoting critical thinking. A written collection of class case studies utilized during class and clinical experiences may also demonstrate scholarship of nursing practice. Case studies may also be written for publication in peer-reviewed journals.

\section{Establishing academic-service partnerships}

The nursing profession is positioned to shape interdependent health care processes and academic systems. The scholarship of practice may be exemplified by the establishment of academic/health organization partnerships. Such partnerships may provide new clinical opportunities for students or new teaching models for patients and their families. Academic / health institution relationships may provide health care opportunities for individuals, families, and communities. The outcomes of our experience with one particular such partnership have been very positive resulting in increased numbers of baccalaureate prepared nurses, and has generated new models of teaching and learning which has been most positive for both students and staff. Such partnerships may also significantly affect patient health outcomes. New research questions may arise out of such partnerships, with new evidence being produced for best practice ${ }^{[15]}$. Written proposals, projects, and outcome data may demonstrate evidence of such scholarship.

\section{Reports compiling and analyzing client programs/ health outcomes}

Ongoing analyses and reports are expected to address patient outcomes or analyze health care systems. Practicing nurse academicians frequently analyze the quality of health care service outcomes and suggest change for practice that impacts the quality of services that our clients receive. One of our faculty submitted a proposal that changed the scheduling of patients for afterhours which was adapted and resulted in great increase in both patient and employer satisfaction. Written analyses, including proposals and outcome reports substantiates such scholarship. Nurse academicians are involved in addressing patient outcome data to promote optimal goals and comprehensive care. Such written analyses of the assessment and evaluation of health systems may provide another source of the scholarship of practice. In addition, as nurses analyze health outcomes, policy papers may be produced that benefit patients and health care outcomes.

\section{Consultation reports}

A nurse academician may be called upon to evaluate other School of Nursing's course of study, curricula and/or the entire program. Advanced practice academicians may also be involved in reviewing evidence based guidelines. Written reports of these reviews is a product of the scholarship of practice, and should be included in promotion packages as such. 


\section{Dissemination of research findings for public awareness}

Traditional research dissemination takes place in peer reviewed journals, and during research conferences. Dissemination of the scholarship of practice may need to be broader, for instance in the public press, television or radio interviews that will reach the public, including legislators ${ }^{[11]}$. This information may influence public policy matters, legislation, and health care reimbursement. Very often, college and university administration view only peer-reviewed vehicles for dissemination of scholarship as acceptable. Legislatures and the general public have limited opportunities to read such professional journals or attend conferences. Nurses are in a unique position to positively impact health care with professional articles written for public awareness and knowledge. These types of activities should also be considered scholarship of practice and an application for the public.

\section{Model program implementation with demonstrated outcomes}

APN/ nurse academicians are well suited to develop and implement evidence based clinical programs in practice settings. Examples as already mentioned, include an oral health program in a group prenatal setting and a peer interactive model stimulating critical thinking in undergraduate clinical settings ${ }^{[8,11]}$. Clinical algorithms, teaching tools designed for targeted clinical populations and applying software for data retrieval or clinical documentation will also improve program processes. Such programs utilize theory and evidence based practice for quality practice. Published articles may provide evidence of this type of practice scholarship, but also administrative letters, program outlines, participant evaluations, and program evaluations may also provide evidence of such scholarship.

\section{Sharing scholarship}

Sharing information and publishing nursing research and ideas promotes improvements in nursing techniques and in nursing care ${ }^{[7]}$. Nurses teach others in various modes, through in-services, poster presentations and podium presentations. Nurses may share new information through local, state or national venues. Knowledge dissemination should include more than just sharing information with other health professionals; such dissemination would benefit interested health care consumers ${ }^{[7]}$. We have found that our college administration recognizes peer-reviewed publications as evidence of scholarship, and is reluctant to recognize national and international podium and poster presentations as primary products of scholarship. It is important that nursing advocate that sharing scholarship through these other venues are appropriate scholarship products.

\section{Summary}

The AACN Position Statement on Defining Scholarship for the Discipline of Nursing "provides standards that clarify and describe a full range of scholarship within the discipline of nursing”" ${ }^{[2]}$. Nursing faculty, particularly those in advanced practice roles need to familiarize themselves with such position statements to better clarify scholarly work. Besides describing the four dimensions of scholarly practice in nursing, this article is meant to stimulate discussion on the importance of recognizing the scholarship of application as it applies to nursing practice as well as provide specific examples for our readership. It is hoped that this article will assist nursing faculty to demonstrate accomplishments in nursing scholarship which are also practice based, multidimensional and comprehensive. Such documentation can then be incorporated into nursing faculty appointment portfolios for review for promotion and tenure.

\section{Acknowledgements}

The authors wish to acknowledge the faculty that we work with, as they are the impetus for pushing the practice of scholarship forward with the college administration. They are each expert teachers as well as expert clinicians. Maintaining as active practice as a faculty member provides a plentitude of case studies for classroom discussion as well as great respect of our students for faculty knowledge and experience. 


\section{Competing interests}

The authors declare that they have no competing interests.

\section{Authors' contributions}

Dr. Peterson as the first author drafted this manuscript and has been responsible for any major revisions and for formatting the manuscript according to author guidelines. Dr. Stevens as the second author has made substantial contributions to the both drafting the manuscript and providing critical appraisal for revisions. Both authors have provided final approval of this manuscript to be submitted for publication.

\section{References}

[1] Thoun DS. Toward an appreciation of nursing scholarship: recognizing our traditions, contributions, and presence. Journal of Nursing Education. 2009; 48(10): 552-556. PMid:19650614 http://dx.doi.org/10.3928/01484834-20090716-01

[2] American Association of Colleges of Nursing. Position Statement on Defining Scholarship for the Discipline of Nursing. 1999. Retrieved 3/30/12 from http:www.aacn.nche. edu/Publications/positions/scholar.htm.

[3] Boyer E. Scholarship reconsidered: priorities for the professoriate. Princeton, NJ: The Carnegie Foundation for the Advancement of Teaching; 1990.

[4] Fisher EM, Riley TA. Fostering the scholarship of discovery and integration for advanced practice education. Nurse Education Perspectives. 2005; 26(6): 348-350. PMid:16430001

[5] Riley JM, Beal J, Levi P, McCausland MP. Revising nursing scholarship. Journal of Nursing Scholarship. 2002; 34(4): $383-389$. PMid:12501743 http://dx.doi.org/10.1111/j.1547-5069.2002.00383.x

[6] Starck PL. Boyer's multidimensional nature of scholarship: a new framework for schools of nursing. Journal of Professional Nursing. 1996; 12(5): 268-276. http://dx.doi.org/10.1016/S8755-7223(96)80006-8

[7] Pape T. Boyer's model of scholarly nursing applied to professional development. AORN Journal. 2000; 71(5):995-1003. http://dx.doi.org/10.1016/S0001-2092(06)61549-4

[8] Stevens J. Promotion of critical thinking in clinical post-conferences: an integrative peer approach. The Journal on Excellence in College Teaching (JECT.). 2009; 20(5): 5-29.

[9] Happell B. Nursing clinical development units-a strategy to promote the relationship between practice and academia. International Journal of Psychiatric Nursing Research. 2006; 11(3): 1322-1330. PMid:16776440

[10] Jacelon CS, Donoghue LC, Breslin E. Scholar in residence: an innovative Application of the scholarship of engagement. Journal of Professional Nursing. 2010; 26(1):61-66.PMid:20129595 http://dx.doi.org/10.1016/j.profnurs.2009.09.004

[11] Stevens J, Iida H. Implementing an oral health program in a group prenatal practice. Journal of Obstetric, Gynecologic and Neonatal Nursing (JOGNN). 2007; 36(6): 581-591. PMid:15784503 http://dx.doi.org/10.1111/j.1552-6909.2007.00189.x

[12] Soukup SM. The center for advanced nursing practice evidence-based practice model: promoting the scholarship of practice. Nursing Clinics of North America. 2000; 35(2): 301-309.PMid:10873242

[13] Burgener SC. Scholarship of practice for a practice profession. Journal of Professional Nursing. 2001; 17(1): 46-54. PMid:11211384 http://dx.doi.org/10.1053/jpnu.2001.20246

[14] Polit DF, Beck CT. Essentials of Nursing Research. $7^{\text {th }}$ edition. Philadelphia: Lippincott, Williams \& Wilkins; 2010.

[15] Bleich MR, Hewlett PO, Miller KL, Bender K. Beyond tradition: synergizing intellectual and material capital to forge the new academic-service partnership. Journal of Professional Nursing. 2004; 20(5): 285-294. PMid:15494961

http://dx.doi.org/10.1016/j.profnurs.2004.07.007 